\title{
MicroRNA-149 inhibits cancer cell malignant phenotype by regulating Akt1 in C4-2 CRPC cell line
}

\author{
JIAHUI ZHAO*, QIANKUN LI*, BINGFU FENG, DECHAO WEI, YILI HAN, \\ MINGCHUAN LI, YONGXING WANG, YONG LUO and YONGGUANG JIANG
}

Department of Urology, Beijing Anzhen Hospital, Capital Medical University, Chaoyang, Beijing 100029, P.R. China

Received January 6, 2021; Accepted August 31, 2021

DOI: 10.3892/or.2021.8209

\begin{abstract}
Prostate cancer (PCa) is an androgen-dependent disease. Androgen receptor (AR) has a crucial role in the development and progression of PCa. Recently, several microRNAs (miRNAs/miRs) involved in AR regulation have been associated with castration-resistant prostate cancer(CRPC), the terminal stage of PCa. Nevertheless, the precise mechanism remains unclear. The present study aimed to identify a novel miR-149 regulatory network and potential therapeutic target for CRPC. It was found that ectopic expression of miR-149 mimic could inhibit AR expression, repress epithelial-mesenchymal transition, induce cell cycle arrest and apoptosis in CRPC cell line C4-2, whereas the miR-149 inhibitor exerted the opposite effects. Furthermore, it was also revealed that miR-149 could reduce the functional activity of the PI3K/Akt1 signaling pathway by targeting Akt1 protein, the key regulatory factor of the PI3K/Akt1 signaling pathway. Knockdown of Akt1 by short hairpin RNA increased apoptosis, reduced proliferation, and restrained migration and invasion in CRPC cells, with the effect of AR inhibition. In conclusion, these results revealed that miR-149 acts as a tumor suppressor in CRPC cell line C4-2 and restrains its progression through the AR signaling pathway by targeting Akt1. The miR-149/Akt1/AR regulatory pathway may represent a novel $\mathrm{PCa}$ therapeutic target.
\end{abstract}

\section{Introduction}

Prostate cancer (PCa) is the fifth most common cancer globally and the leading cause of cancer in men (1). More than

Correspondence to: Dr Yong Luo or Dr Yongguang Jiang, Department of Urology, Beijing Anzhen Hospital, Capital Medical University, 2 Anzhen Lu Road, Anzhenli, Chaoyang, Beijing 100029, P.R. China

E-mail: luoyonganzhen@163.com

E-mail: yongguangjiang@126.com

*Contributed equally

Key words: castration-resistant prostate cancer, microRNA-149, PI3K/Akt signaling pathway, microRNAs
$80 \%$ of patients with PCa die due to bone metastases (2). Androgen deprivation therapy (ADT) is the primary treatment for advanced PCa. However, most patients with PCa with metastasis receiving ADT develop castration-resistant prostate cancer (CRPC) within 1-3 years $(3,4)$.

Despite the lack of circulating androgens in patients with $\mathrm{CRPC}$, the androgen receptor (AR) signal is considered the driving force of cancer growth and invasion (3). Thus, drugs reducing the level of androgen (abiraterone) and inhibiting AR (enzalutamide) activity have been recommended for CRPC treatment. Unfortunately, acquired drug resistance targeting the AR ligand-binding domain is a common clinical problem $(5,6)$. Recently, several studies have revealed a fundamental relationship between the AR and PI3K/Akt signaling pathway in CRPC development and progression (6,7). It has been revealed that loss of PTEN, the key regulator of the PI3K/Akt signaling pathway, may decrease transcription of AR target genes by inhibiting the negative regulators of AR activity in PCa (8). Treatment with the AR inhibitor enzalutamide in a PTEN loss mouse model enhanced PI3K/Akt signaling activity by reducing the expression of peptidyl-prolyl cis-trans isomerase FKBP5 (FKBP5) (9).

Several clinical reports have also revealed that the AR and PI3K/Akt1 signaling pathways could compensate for each other in inhibition of either pathway alone in patients with CRPC $(6,10)$. It is speculated that the PI3K/Akt signaling pathway that participates in the mechanism of resistance to ADT is also involved in the AR signaling pathway in CRPC (10). MicroRNAs (miRNAs/miRs) are small non-coding RNA molecules that regulate the expression of target mRNA at a post-transcriptional level by binding to the complementary sites within the 3' untranslated region. miR-149 has been found to serve as a tumor suppressor in various cancers, such as gastric, lung, breast and renal cell carcinoma $(11,12)$. Loss of miR-149 has been associated with the development of renal cell carcinoma, while elevated expression of miR-149 has been reported to be important in the development of nasopharyngeal carcinoma (13). Recently, several studies have also revealed that miR-149 is involved in the development and progression of CRPC $(14,15)$. Fujii et al (16) reported that miR-149 targets syndecan-1 to control cell proliferation and invasion by regulating the expression of Oct4 and SOX2 in $\mathrm{PCa}$.

In our previous study, we revealed that PCa cells contain a small subset of cells, called side population (SP). These cells possess a much greater capacity of colony formation 
and tumorigenic potential than non-SP (17). Furthermore, we also revealed that the expression of miR-149 was significantly different in SP cells and non-SP cells of the TSU CRPC cell line (17). Yet, the precise mechanism through which miR-149 regulates PCa progression still remains unclear.

The androgen-independent Lymph Node Carcinoma of the Prostate ( $\mathrm{LNCaP}$ ) subline, $\mathrm{C} 4-2$ cells, were obtained from LNCaP tumors maintained in castrated hosts. This tumor subline has been found to acquire metastatic potential targeting the bone when orthotopically inoculated into both castrated and intact athymic male nude mice (18). In the current study, the role of miR-149 in the malignant phenotype and its molecular mechanism were further investigated in CRPC cell line C4-2.

\section{Materials and methods}

Cell culture, transfection and reagent. The human prostate cells C4-2 were purchased from the Tongpai (Shanghai) Biotechnology Co., Ltd., and cultured in RPMI-1640 (Cytiva) medium supplemented with $10 \%$ FBS (Thermo Fisher Scientific, Inc.), $100 \mu \mathrm{g} / \mathrm{ml}$ streptomycin (Sigma-Aldrich; Merck KGaA) and $100 \mathrm{U} / \mathrm{ml}$ penicillin (Sigma-Aldrich; Merck $\mathrm{KGaA}$ ) in a humidified atmosphere containing $5 \% \mathrm{CO}_{2} / 95 \%$ air at $37^{\circ} \mathrm{C}$. All the miRNAs, including mimics control, inhibitor control, miR-149-5p mimic and miR-149-5p inhibitor, were acquired from Tongpai Biotechnology Co., Ltd. (Shanghai, China). The $50 \mathrm{nM}$ mimic (miR-149-5p mimic and mimics control) and $100 \mathrm{nM}$ inhibitor (miR-149-5p inhibitor and inhibitor control) were transfected into C4-2 cells using Lipofectamine 2000 (Invitrogen; Thermo Fisher Scientific, Inc.) according to the manufacturer's protocol. The sequences were as follows: miR-149-5p mimic, 5'-UCUGGCUCCGUG UCUUCACUCCC-3'; mimics control, 5'-UUCUCCGAACGU GUCACGUTT-3'; miR-149-5p inhibitor, 5'-GGGAGUGAA GACACGGAGCCAGA-3'; and inhibitor control, 5'-CAG UACUUUUGUGUAGUACAA-3'. Akt1 specific short hairpin (sh)RNA against Aktl and the corresponding negative control were constructed in the pSUPER vector (provided by Professor He Dalin, Xi'an Jiaotong University, Xi'an, China), and the sequences for Akt1 shRNA were as follows: 5'-TCGCGT GACCATGAACGAGTTTTTCAAGAGAAAACTCGTTCA TGGTCACGCTTTTTTCTCGAG-3'. Akt1 shRNA (4 $\mu \mathrm{g})$ was transfected into C4-2 cells using Lipofectamine ${ }^{\circledR} 2000$ (Invitrogen; Thermo Fisher Scientific, Inc.) according to the manufacturer's protocol. After $72 \mathrm{~h}$ of transfection, cells were subjected to reverse transcription-quantitative polymerase chain reaction PCR (RT-qPCR), western blotting and Cell Counting Kit-8 (CCK-8) assay, as described below.

$R T-q P C R$. Total RNA of PCa cells was extracted by TRIzol (Invitrogen; Thermo Fisher Scientific, Inc.) according to the manufacturer's instructions. To measure the Akt1 and AR mRNA expression, cDNA synthesis was conducted with the PrimeScript RT Master Mix (Takara Biotechnology Co., Ltd.), according to the manufacturer's protocol. The cDNA product of PCa cells was then subjected to qPCR with SYBR Premix Ex Taq (Takara Biotechnology Co., Ltd.) and GAPDH served as the control. The qPCR conditions were as follows: $35-45$ cycles of $94^{\circ} \mathrm{C}$ for $30 \mathrm{sec}$, followed by $55-63^{\circ} \mathrm{C}$ for
$30 \mathrm{sec}$. Primer sequences used for qPCR are shown in Table I. The data were analyzed using the $2^{-\Delta \Delta \mathrm{Cq}}$ method (19).

Western blotting. Total protein was obtained from cultured cells using ice-cold lysis buffer containing $0.1 \%$ sodium dodecyl sulfate, $1 \%$ NP-40, $0.1 \%$ sodium dodecyl sulfate and $200 \mu \mathrm{g} / \mathrm{ml}$ phenylmethanesulfonyl fluoride. Insoluble materials were removed by ultracentrifugation at $15,000 \mathrm{x} \mathrm{g}$ for $30 \mathrm{~min}$ at $4^{\circ} \mathrm{C}$. The concentration of the extracted protein was measured spectrophotometrically with Coomassie G-250. Total protein $(50 \mu \mathrm{g})$ was loaded in each lane and resolved on a $12 \%$ SDS-PAGE gel. The proteins were transferred onto PVDF membranes using a wet transfer method following polyacrylamide gel electrophoresis, and then blocked with 3\% bovine serum albumin (Santa Cruz Biotechnology, Inc.) for $1 \mathrm{~h}$ at room temperature and washed with Tris-buffered saline and $0.1 \%$ Tween-20 three times. Samples were incubated at $4^{\circ} \mathrm{C}$ overnight with the following primary antibodies: Akt1 (1:1,000; cat. no. 2938S; Cell Signaling Technology, Inc.), p-Akt1 S473 (1:1,000; cat. no. 9018S; Cell Signaling Technology, Inc.), AR (1:1,000; cat. no. 5153S; Cell Signaling Technology, Inc.), PTEN (1:1,000; cat. no. 9559S; Cell Signaling Technology, Inc.), p-PI3K (1:1,000; cat. no. 3821S; Cell Signaling Technology, Inc.), total PI3K (1:1,000; cat. no. 4249S; Cell Signaling Technology, Inc.), mTOR (1:1,000; cat. no. 2983S; Cell Signaling Technology, Inc.), p-mTOR (1:1,000; cat. no. 2974S; Cell Signaling Technology, Inc.), PSA (1:1,000; cat. no. 5365; Cell Signaling Technology, Inc.), FKBP5 (1:1,000; cat. no. 12210; Cell Signaling Technology, Inc.), E-cadherin (1:1,000; cat. no. sc-8426; Santa Cruz Biotechnology, Inc.), Snail (1:1,000; cat. no. sc-271977; Santa Cruz Biotechnology, Inc.), Vimentin (1:4,000; cat. no. sc-6260; Santa Cruz Biotechnology, Inc.) and $\beta$-actin (1:4,000; cat. no. sc-47778; Santa Cruz Biotechnology, Inc.). Then, membranes were incubated with horseradish peroxidase-conjugated secondary antibodies (1:4,000; cat. nos. A0208 and A0216; Beyotime Institute of Biotechnology) at room temperature for $2 \mathrm{~h}$. The western bands were visualized using ECL detection reagent (Pierce; Thermo Fisher Scientific, Inc.). For semi-quantification of band intensity, appropriate films were scanned and band densities were determined using Quantity One software (version 4.6.6; Bio-Rad Laboratories, Inc.), normalized against GAPDH, and presented as a ratio of control.

CCK-8 assay. The PCa cells were incubated for $24 \mathrm{~h}$ and then collected for the preparation of a cell suspension. Cells were then transferred into a 96 -well plate (2,000 cells/well); group contained three replicate wells. The proliferation potency of PCa was evaluated at four time points: $0,1,2$ and 3 days after the implantation. After each time point, cells were treated with the CCK-8 solution (Dojindo Molecular Technologies, Inc.) for $2 \mathrm{~h}$. The absorbance at $450 \mathrm{~nm}$ wavelength was determined using a Multilabel Reader (Thermo Fisher Scientific, Inc.).

Transwell migration and invasion assays. The PCa cells were resuspended in DMEM (Gibco; Thermo Fisher Scientific, Inc.) without FBS, and the cell suspension containing $1 \times 10^{5}$ cells was transferred into the upper compartment of Transwell inserts (Costar; Corning, Inc.) in 24-well plates, while the lower compartment was covered with DMEM that 
Table I. Primer sequences used for reverse transcription-quantitative PCR.

\begin{tabular}{lll}
\hline Gene & \multicolumn{1}{c}{ Forward $\left(5^{\prime} \rightarrow 3^{\prime}\right)$} & \multicolumn{1}{c}{ Reverse $\left(5^{\prime} \rightarrow 3^{\prime}\right)$} \\
\hline miR-149 & GCGCTCTGGCTCCGTGTCTTC & GTGCAGGGTCCGAGGT \\
U6 & CTCGCTTCGGCAGCACATATACT & ACGCTTCACGAATTTGCGTGTC \\
AR & CTTCCCTCCCTATCTAACCCTC & TCTAAACTTCCCGTGGCATAA \\
Akt1 & TCCTCCTCAAGAATGATGGCA & GTGCGTTCGATGACAGTGGT \\
mTOR & GCGAACCTCAGGGCAAGAT & TGACTCATCTCTCGGAGTTCCA \\
GAPDH & AAGGTGAAGGTCGGAGTCAAC & GGGGTCATTGATGGCAACAATA
\end{tabular}

miR, microRNA; AR, androgen receptor.

was supplemented with $10 \% \mathrm{FBS}$. After incubation at $37^{\circ} \mathrm{C}$ for $24 \mathrm{~h}$, non-migratory cells were removed by cotton swab, while the migratory cells were fixed in $4 \%$ paraformaldehyde and stained with $0.5 \%$ crystal violet at room temperature for $10 \mathrm{~min}$. Cell migration was analyzed by counting the migratory cells in five random visual fields per plate using a light microscope (Olympus Corporation). The Transwell invasion assay was performed using the same procedures as those for the migration assay, except the 24-well plates were precoated with Matrigel $\left(37^{\circ} \mathrm{C}\right.$ for $\left.30 \mathrm{~min}\right)$.

Cell cycle assay. Cells were collected $36 \mathrm{~h}$ after transfection and then centrifuged at $160 \mathrm{x}$ g for $5 \mathrm{~min}$. Subsequently, cells were fixed with $500 \mu 170 \%$ cold ethanol for $4^{\circ} \mathrm{C}$ at $2 \mathrm{~h}$, stained with $500 \mu \mathrm{l} \mathrm{PI} / \mathrm{RNase}$ staining solution, and incubated at $37^{\circ} \mathrm{C}$ for $30 \mathrm{~min}$ in the dark. The cell samples were analyzed by flow cytometry using a FACScan flow cytometer (BD Biosciences). All the results were analyzed using FlowJo software (version 10; FlowJo LLC).

Apoptosis assay. The early apoptosis assay of the PCa cells was performed using an Annexin V-FITC/PI staining kit (Nanjing Jiancheng Bioengineering Research Institute), according to the manufacturer's instructions. The PCa cells were cultured in 12-well plates and then resuspended in binding buffer $36 \mathrm{~h}$ after transfection, followed by staining with Annexin V-FITC/PI in the dark at room temperature for $15 \mathrm{~min}$.

Statistical analysis. All experiments were independently performed in triplicate. Data are presented as the mean \pm standard deviation. Data analysis was performed using SPSS software version 13.0 for Windows (SPSS, Inc.). Results were compared by one-way ANOVA followed by post hoc Tukey's tests. $\mathrm{P}<0.05$ was considered to indicate a statistically significant difference.

\section{Results}

Aktl is regulated by miR-149 in CRPC cell line C4-2. To clarify the biological role of miR-149 in PCa, miR-149 mimic and miR-149 inhibitor were transfected into C4-2 cells, after which the transfection efficiency was confirmed by RT-qPCR (Fig. 1A). The results showed that miR-149 mimic significantly increased the expression levels of miR-149, while miR-149 inhibitor significantly decreased the expression levels of
miR-149 $(\mathrm{P}<0.05)$. Furthermore, RT-qPCR assay was carried out to investigate the influence of miR-149 on the expression of Akt1 and mTOR in C4-2 cells. As shown in Fig. 1B and C, transfection of miR-149 mimics significantly reduced the mRNA expression levels of Akt1 and mTOR in C4-2 cells, while the miR-149 inhibitor exerted the opposite effect $(\mathrm{P}<0.05)$. The effect of miR-149 mimic and miR-149 inhibitor on the protein expression levels of Akt1, p-Akt1, p-PI3K, PI3K, p-mTOR, mTOR and PTEN were also investigated by western blotting (Fig. 1G). As a result, the expression levels of Akt1, p-Akt1 and p-mTOR were significantly decreased in C4-2 CRPC cells transfected with miR-149 mimic, while miR-149 inhibitor exerted the opposite effects compared with the NC groups $(\mathrm{P}<0.05$; Fig. 1D-F). In addition, while $\mathrm{p}-\mathrm{Akt}$ and $\mathrm{p}$-mTOR expression was altered when compared with $\beta$-actin, $\mathrm{p}$-PI3K, $\mathrm{p}$-Akt and $\mathrm{p}$-mTOR expression did not differ when compared with total protein in these groups $(\mathrm{P}>0.05$; Fig. 1H-J). Moreover, the expression of PI3K, p-PI3K and PTEN did not significantly differ in these groups. The present results revealed that miR-149 overexpression did not affect the protein expression of PI3K, p-PI3K and PTEN, which regulate Akt1 expression in the PI3K/Akt signaling pathway (data not shown). Collectively, these results suggested that miR-149 targeted Akt1 and negatively regulated the PI3K/AKT signaling pathway in PCa cells.

$A R$ is regulated by Aktl in CRPC cell line C4-2. As AR has an important role in $\mathrm{PCa}$ initiation and progress (3), it was examined whether Akt1 participates in the AR signaling pathway and thereby regulates carcinogenesis, including cancer progression. Initially, Akt1 was knocked down in C4-2 cells using RNA interference and proof of transfection was confirmed (Fig. S1). Western blotting results indicated that the protein expression of p-Akt1 was significantly decreased in the Akt1 KD + miR-149 mimic NC group compared with the Akr1 $\mathrm{NC}+$ miR-149 mimic NC group $(\mathrm{P}<0.01)$. Furthermore, the effects of Akt1 shRNA and miR-149 mimics on the expression levels of AR and AR-driven proteins were investigated. As a result, the protein expression levels of AR, PSA and FKBP5 were significantly decreased in the Akt1 KD + miR-149 mimic $\mathrm{NC}$, Akt1 $\mathrm{NC}+\mathrm{miR}-149$ mimic and Akt1 KD + miR-149 mimic groups compared with the Akt1 NC + miR-149 mimic $\mathrm{NC}$ group ( $\mathrm{P}<0.01$; Fig. $2 \mathrm{~A}$ and $\mathrm{B})$. Collectively, these results suggested that miR-149 targeted Akt1 and negatively regulated the AR signaling pathway in PCa cells. 
A
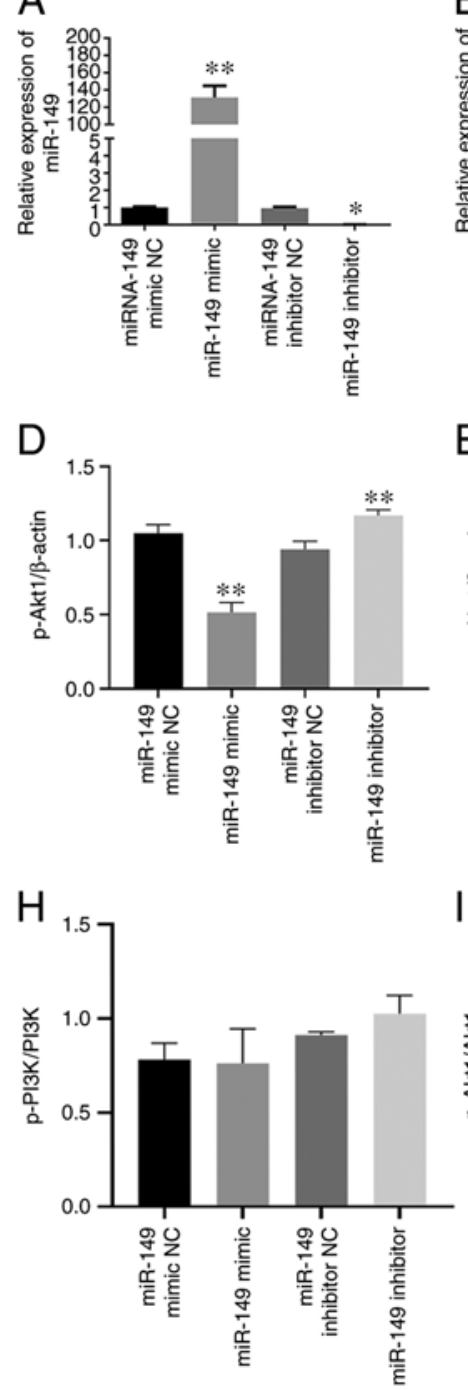

$\mathrm{B}$

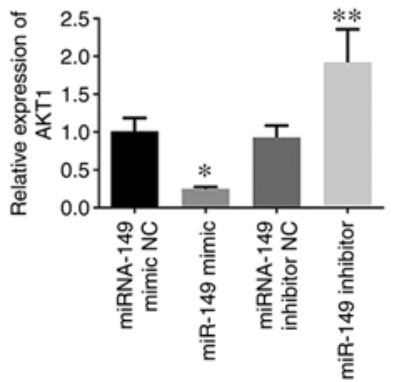

E

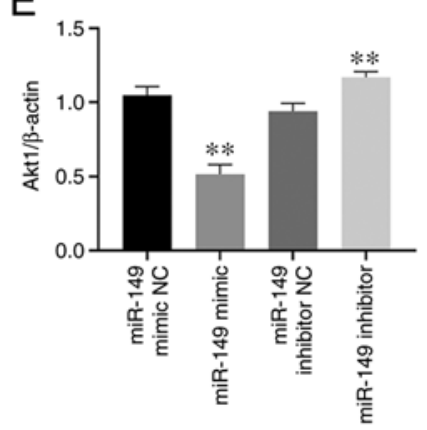

I

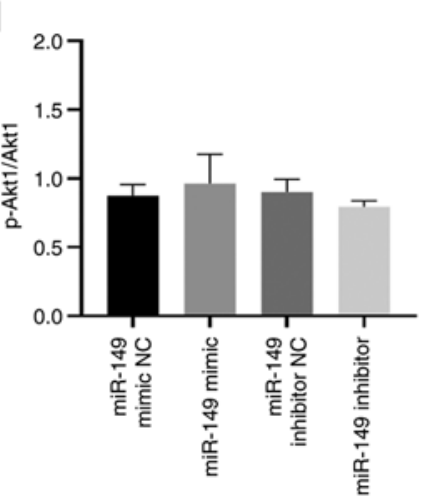

C

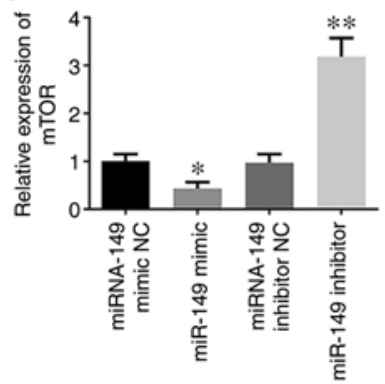

$\mathrm{F}$

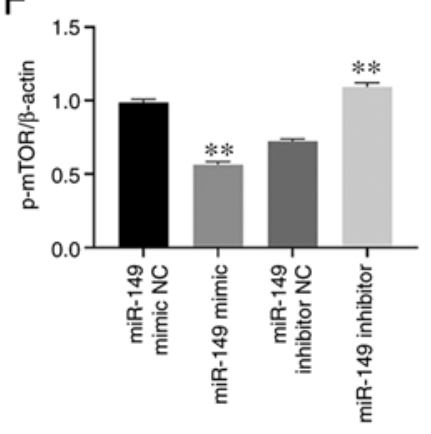

$J$

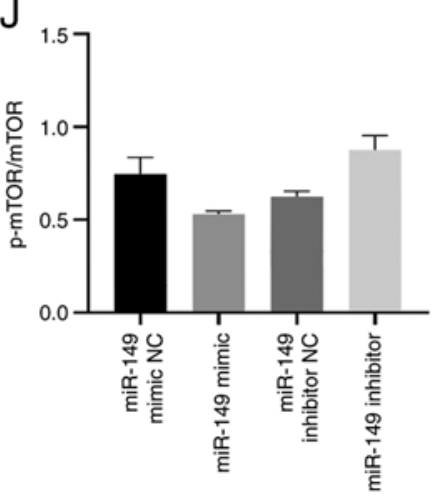

G
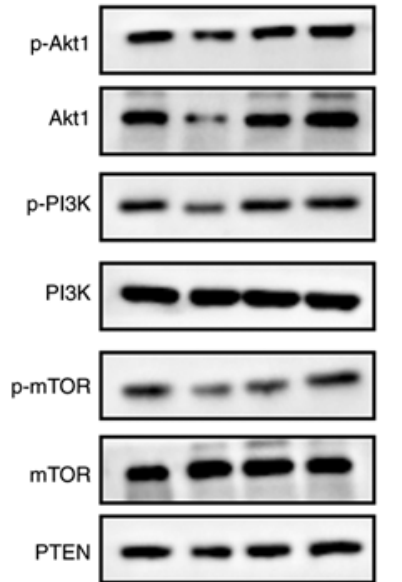

$\beta$-actin

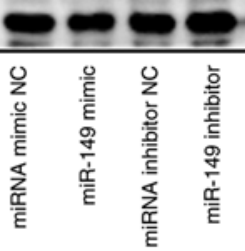

Figure 1. Akt1 is regulated by miR-149 in castration-resistant prostate cancer cells. Reverse transcription-quantitative PCR analysis of (A) miR-149, (B) Akt1 and (C) mTOR mRNA expression levels in C4-2 cells transfected with miR-149 mimic and miR-149 inhibitor. Semi-quantification of western blotting results demonstrated the expression of (D) p-Akt1/ $\beta$-actin, (E) Akt1/ $\beta$-actin and (F) p-mTOR/ $\beta$-actin. (G) Western blot analysis of Akt, p-Akt, PI3K, p-PI3K, p-mTOR, mTOR and PTEN expression in C4-2 cells transfected with miR-149 mimic and miR-149 inhibitor. Semi-quantification of western blotting results demonstrated the expression of $(\mathrm{H})$ p-PI3K/PI3K, (I) p-Akt1/Akt1 and (J) p-mTOR/mTOR. Data are expressed as the mean \pm standard deviation ( $=3$ ); each bar represents the mean of three independent experiments carried out in triplicate. ${ }^{*} \mathrm{P}<0.05,{ }^{* *} \mathrm{P}<0.01 \mathrm{vs}$. NC group. miR, microRNA; $\mathrm{p}-$, phosphorylated; $\mathrm{NC}$, negative control.

Effects of miR-149 and Aktl-shRNA on cell proliferation and apoptosis in CRPC cell line C4-2. To confirm the tumor-suppressive role of miR-149, ectopic expression assays were carried out by miRNA and shRNA transfection into PCa cells. The CRPC cell line C4-2 was transfected with miR-149 mimic and Akt1-shRNA. CCK-8 assay was performed to determine the influence of miR-149 and Akt1-shRNA on CRPC cell proliferation. As a result, the CCK- 8 assay showed that proliferation was significantly decreased in the Akt1 KD + miR-149 mimic NC, Akt1 NC + miR-149 mimic and Akt1 KD + miR-149 mimic groups compared with the Akt1 NC + miR-149 mimic NC group (P<0.01; Fig. 3). FACS analysis was also performed to evaluate the effect of miR-149 mimic and Akt1-shRNA transfection on the apoptosis of CRPC cells. The data indicated that apoptosis of C4-2 cells was significantly enhanced in the Akt1 KD + miR-149 mimic NC, Akt1 NC + miR-149 mimic and Akt1 KD + miR-149 mimic groups compared with the Akt1 $\mathrm{NC}+$ miR-149 mimic NC group ( $\mathrm{P}<0.01$; Fig. $4 \mathrm{~A}$ and $\mathrm{B})$. In addition, with the cell cycle assay results, there was a significant increase of the G1 cell proportion in the Akt1 KD + miR-149 mimic NC, Akt1 NC + miR-149 mimic and Akt1 KD + miR-149 mimic groups compared with the Akt1 $\mathrm{NC}+$ miR-149 mimic NC group ( $\mathrm{P}<0.01 ;$ Fig. 4C-F).

Effects of miR-149 and Akt1-shRNA on cell migration and invasion in CRPC cell line C4-2. To investigate the biological function of miR-149 on the aggressiveness of CRPC cells, Transwell assays were performed to investigate the effect of miR-149 and Akt1-shRNA on CRPC cell migration and invasion. Results of the Transwell assay with or without Matrigel showed that migration and invasion of C4-2 cells were significantly inhibited in the Akt1 KD + miR-149 mimic NC, Akt1 NC + miR-149 mimic and Akt1 KD + miR-149 mimic 
A
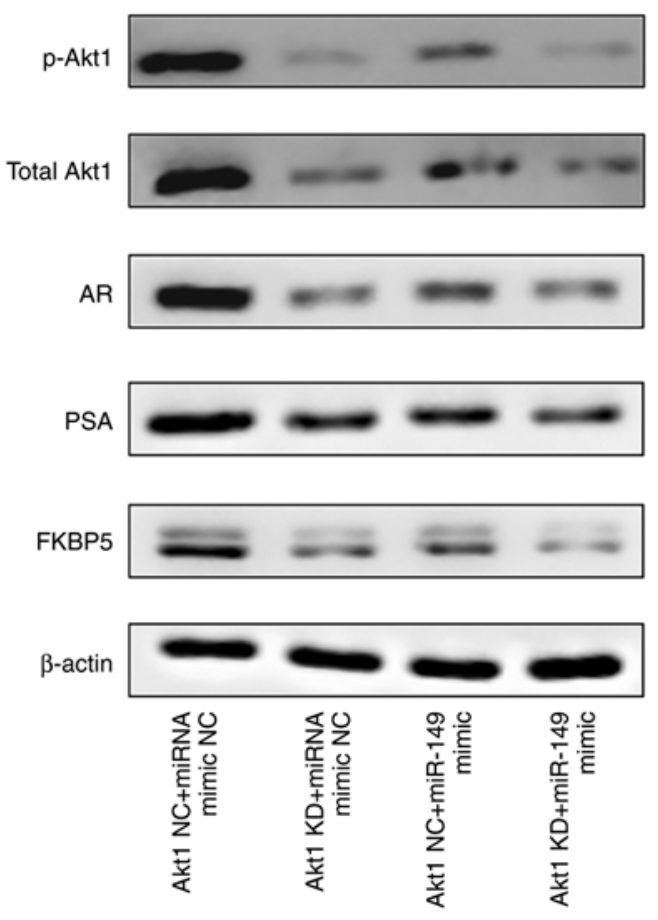
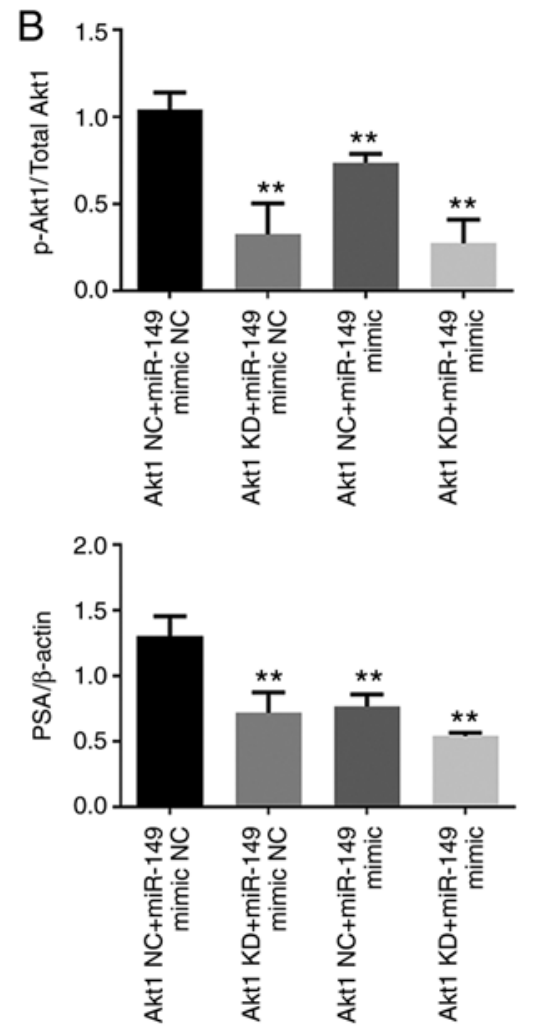
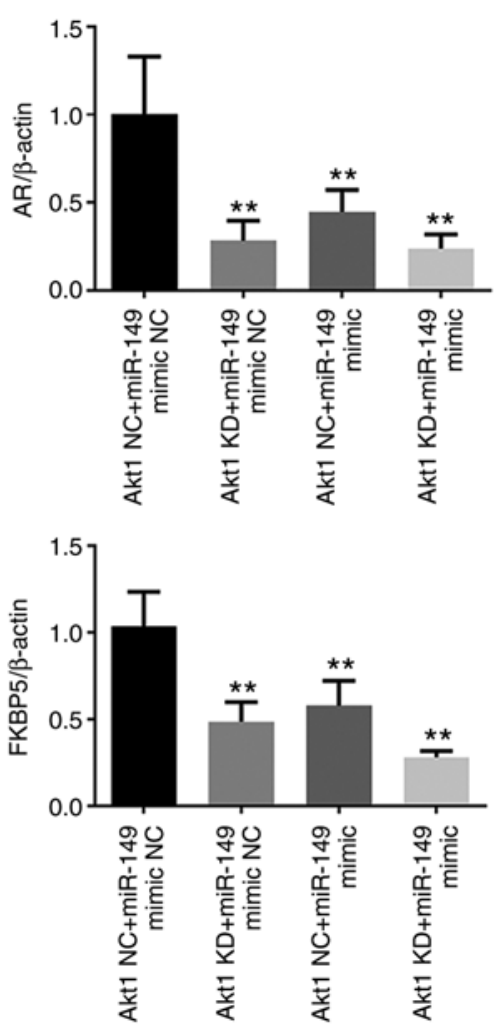

Figure 2. AR is regulated by Akt1 in the castration-resistant prostate cancer cell line. (A) Western blot analysis of p-Akt1, total Akt1, AR, PSA and FKBP5 expression in C4-2 cells transfected with miR-149 mimic and miR-149 inhibitor. (B) Semi-quantification of western blotting results demonstrated the expression of $\mathrm{p}$-Akt1/total Akt1, AR/ $\beta$-actin, PSA/ $\beta$-actin and FKBP5/ $\beta$-actin. Data are expressed as the mean \pm standard deviation $(\mathrm{n}=3)$. ${ }^{* *} \mathrm{P}<0.01 \mathrm{vs}$. Akt1 NC + miR-149 mimic NC group. AR, androgen receptor; miR, microRNA; p-, phosphorylated; NC, negative control; FKBP5, peptidyl-prolyl cis-trans isomerase FKBP5; KD, knockdown.

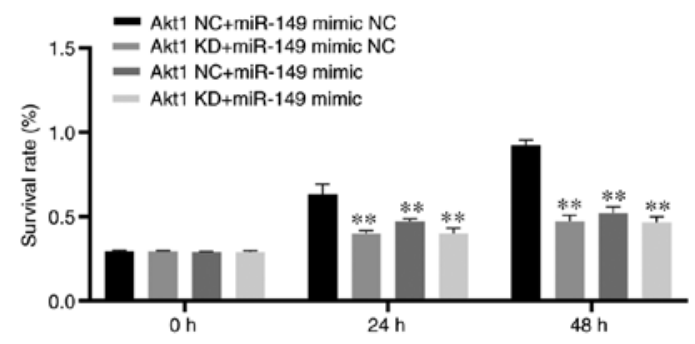

Figure 3. Survival rate of C4-2 cells following transfection. Cell Counting Kit-8 assay was performed to investigate the cellular proliferation of C4-2 cells following transfection with Akt1 NC + miR-149 mimic NC, Akt1 $\mathrm{KD}+$ miR-149 mimic NC, Akt1 NC + miR-149 mimic or Akt1 KD + miR-149 mimic. ${ }^{* *} \mathrm{P}<0.01$ vs. Akt1 NC + miR-149 mimic NC group. miR, microRNA; $\mathrm{NC}$, negative control; KD, knockdown.

groups compared with the Akt1 $\mathrm{NC}+\mathrm{miR}-149$ mimic $\mathrm{NC}$ group (P<0.05; Fig. 5A-D).

EMT has an important role during tumor cell invasion (20). To assess the effect of miR-149 on EMT, E-cadherin (epithelial marker), Snail and Vimentin (mesenchymal markers) expression levels were analyzed in C4-2 cells. Significantly elevated expression of E-cadherin, and significantly reduced expression levels of Vimentin and Snail were observed in the Akt1 KD + miR-149 mimic NC, Akt1 NC + miR-149 mimic and Akt1 KD + miR-149 mimic groups compared with the Akt1 NC + miR-149 mimic NC group $(\mathrm{P}<0.05$, Fig. 6A-D), which indicated that transfection with miR-149 mimics and
Akt1-shRNA inhibited the migratory and invasive abilities of C4-2 cells by repressing EMT.

\section{Discussion}

miR-149 has been implicated in tumor progression by regulating cell proliferation, migration, invasion and chemoresistance (21). It has been reported that downregulation of miR-149 is associated with advanced tumor progression and poor prognosis of human hepatocellular carcinoma (HCC). Furthermore, a multivariate analysis performed in a previous study found that miR-149 expression was an independent prognostic factor for poor 5-year disease-free survival and 5-year overall survival in HCC (22). In addition, miR-149-3p has a high capacity to discriminate between patients with melanoma and healthy controls, making it suitable to be used in early melanoma diagnosis (23).

To date, only a limited number of studies have reported on the effect of miR-149 on the malignant characteristics of PCa. In our previous study, it was revealed that the ectopic expression of miR-149 mimic could significantly decrease the capacity of proliferation and colony formation in TSU-derived SP cells, promote apoptosis and inhibit the growth rate of tumors in vitro (17). In the current study, the potential role and functional mechanism of miR-149 in the development of CRPC was further investigated. These results revealed that ectopic expression of miR-149 mimic could induce cell cycle arrest and apoptosis of CRPC cells. As malignancies are associated with 


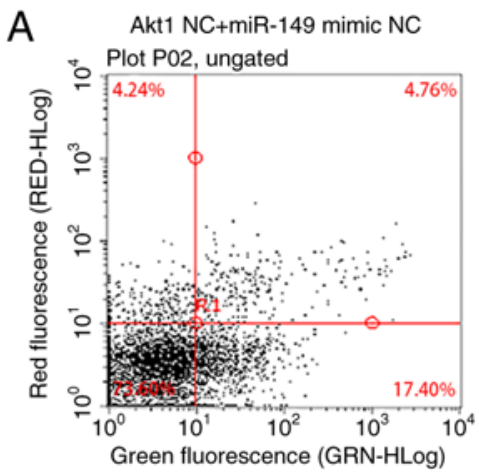

Akt1 NC+miR-149 mimic
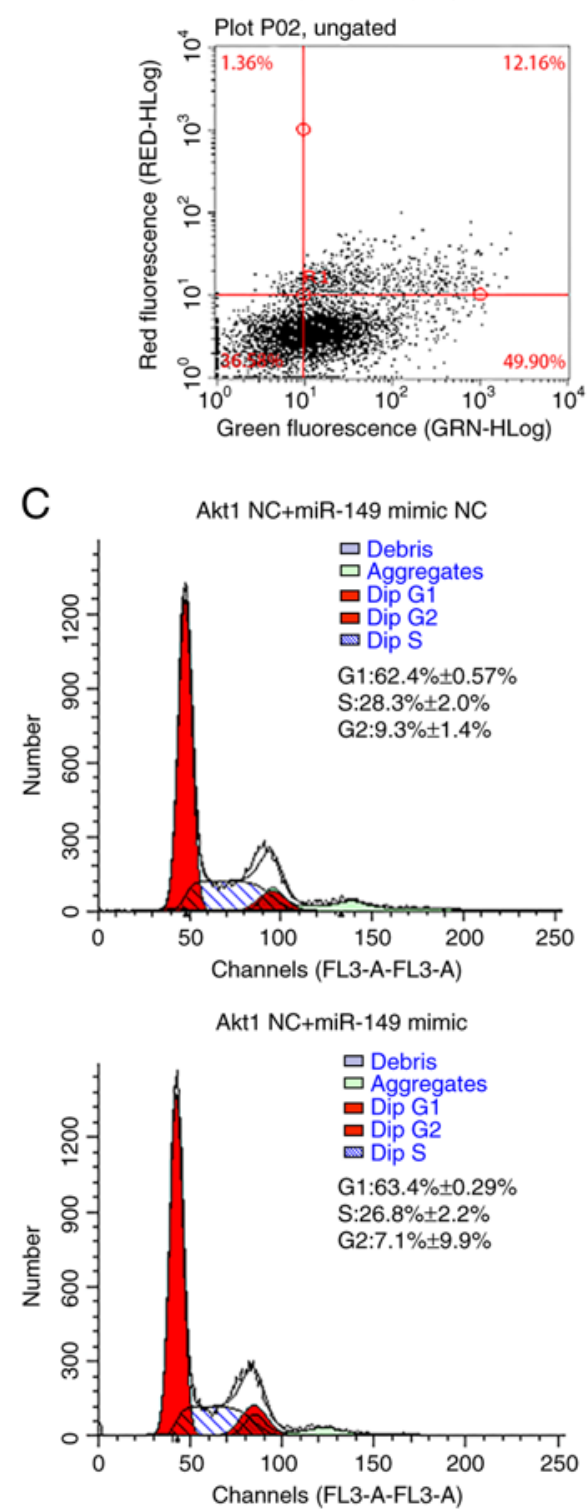

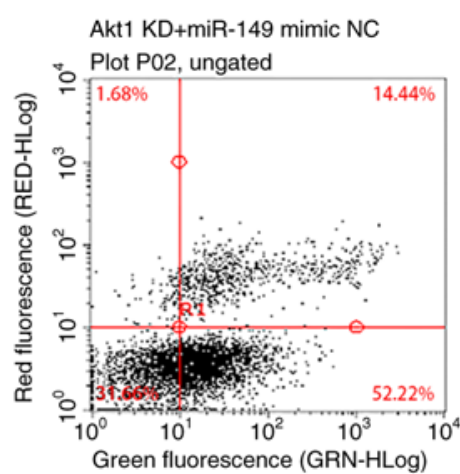

Akt1 KD+miR-149 mimic
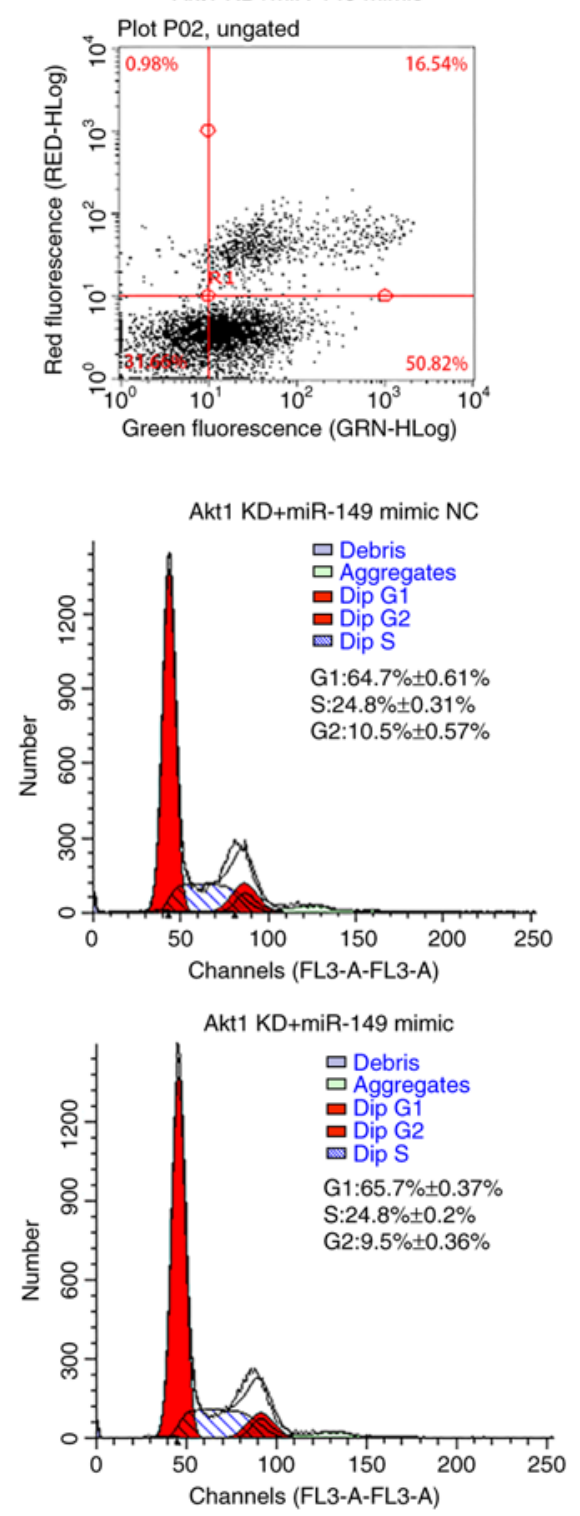
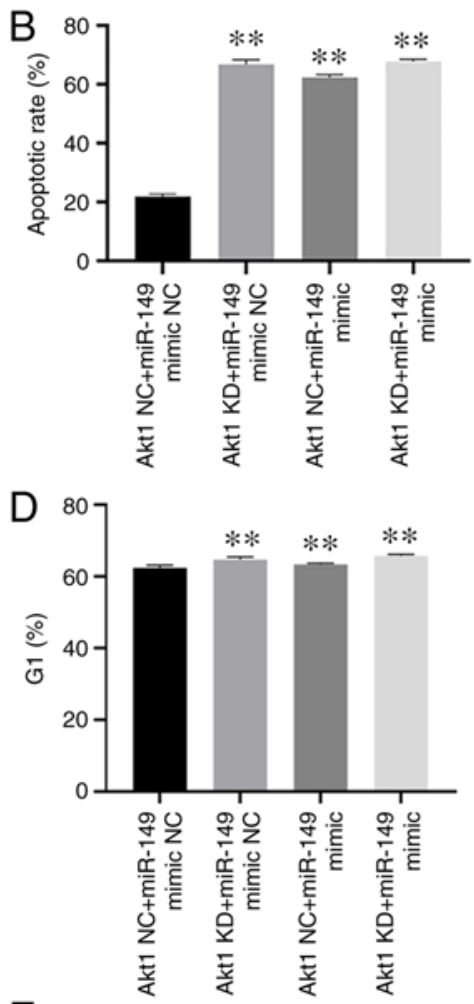

E
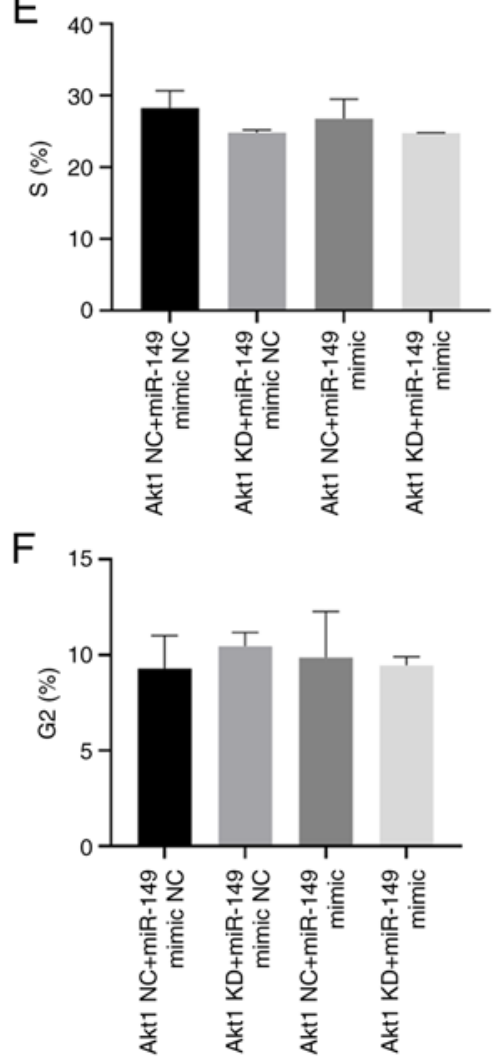

Figure 4. Effects of miR-149 on cell proliferation and apoptosis in castration-resistant prostate cancer cell line. (A and B) The apoptosis rate in C4-2 cells transfected with Akt1 NC + miR-149 mimic NC, Akt1 KD + miR-149 mimic NC, Akt1 NC + miR-149 mimic or Akt1 KD + miR-149 mimic. (C-F) Flow cytometry analysis of cell cycle distribution in C4-2 cells transfected with Akt1 NC + miR-149 mimic NC, Akt1 KD + miR-149 mimic NC, Akt1 NC + miR-149 mimic or Akt1 KD + miR-149 mimic. Data are expressed as the mean \pm standard deviation $(n=3)$. Results were compared by one-way ANOVA followed by Tukey's post hoc test. ${ }^{* *} \mathrm{P}<0.01$ vs. Akt1 NC + miR-149 mimic NC group. miR, microRNA; NC, negative control; KD, knockdown.

increased cancer cell proliferation and invasion, the present study also demonstrated that ectopic miR-149 mimic resulted in an inhibition of PCa proliferation and invasion. EMT is an essential process in cancer progression and metastasis, characterized by changes in epithelial and mesenchymal marker gene expression and changes in cell morphology (20). Emerging 
A

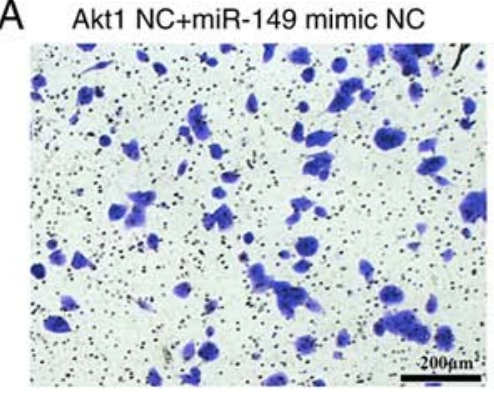

Akt1 NC+miR-149 mimic

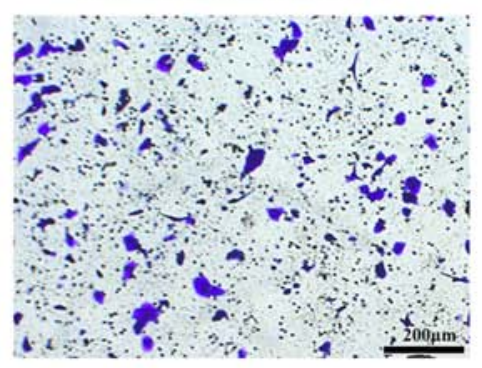

C Akt1 NC+miR-149 mimic NC

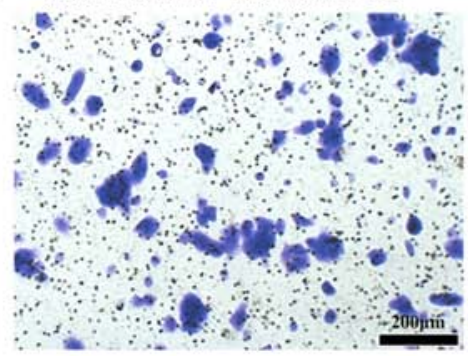

Akt1 NC+miR-149 mimic

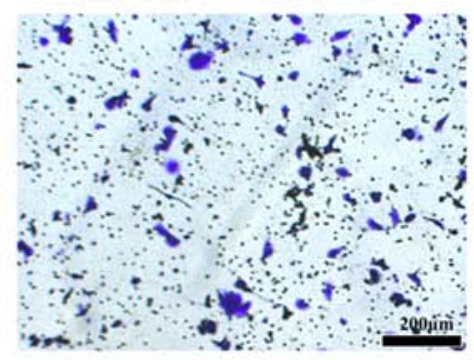

Akt1 KD+miR-149 mimic NC

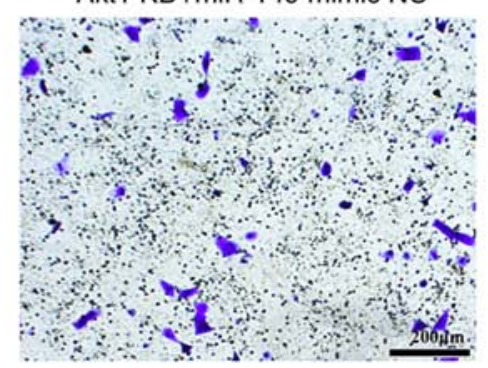

Akt1 KD+miR-149 mimic

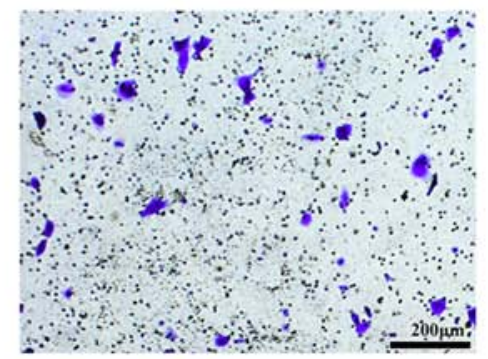

Akt1 KD+miR-149 mimic NC

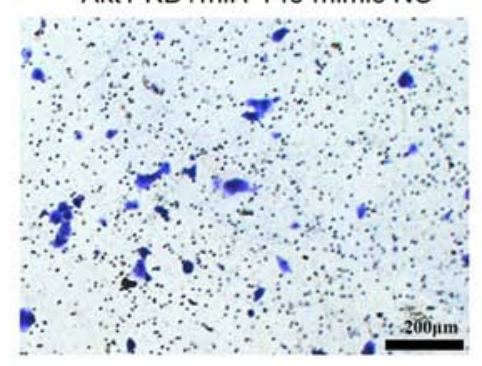

Akt1 KD+miR-149 mimic

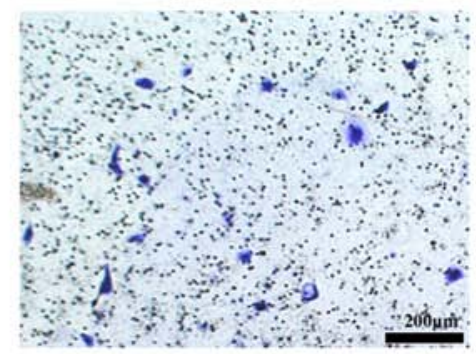

B

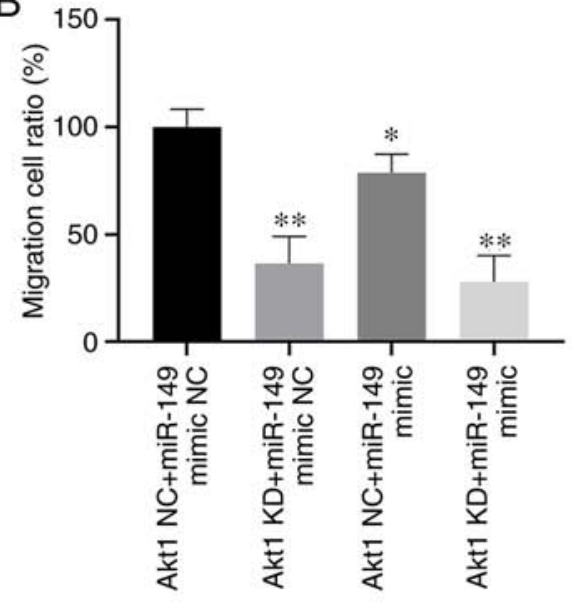

$\mathrm{D}$

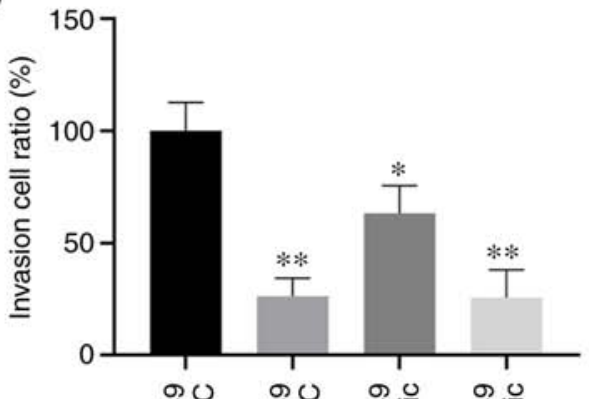

Figure 5. Effects of miR-149 on cell migration and invasion in CRPC cell line. CRPC cells were seeded onto Matrigel-coated or non-Matrigel-coated Transwell chambers for $48 \mathrm{~h}$. The number of cells on the underside of the filter was determined after $48 \mathrm{~h}$. (A) The effect of transfection with Akt1 NC + miR-149 mimic NC, Akt1 KD + miR-149 mimic NC, Akt1 NC + miR-149 mimic or Akt1 KD + miR-149 mimic on cell migration. (B) Transfection with miR-149 mimics or Akt1 shRNA resulted in significant inhibition of C4-2 cell migration. (C) The effect of transfection with Akt1 NC + miR-149 mimic NC, Akt1 KD + miR-149 mimic NC, Akt1 NC + miR-149 mimic or Akt1 KD + miR-149 mimic on cell invasion. (D) Transfection with miR-149 mimics or Akt1 shRNA resulted in significant inhibition of C4-2 cell invasion. Scale bar, $200 \mu \mathrm{m}$. Data are expressed as the mean \pm standard deviation $(\mathrm{n}=3) .{ }^{*} \mathrm{P}<0.05,{ }^{* *} \mathrm{P}<0.01 \mathrm{vs}$. Akt1 NC + miR-149 mimic NC group. miR, microRNA; NC, negative control; KD, knockdown; CRPC, castration-resistant prostate cancer; shRNA, short hairpin RNA.

evidence has indicated that miRNAs have a vital role in the regulation of progression and EMT in numerous types of cancer cells (24). In the current study, it was observed that transfection with the miR-149 mimic could increase the expression of epithelial markers and decrease the expression of mesenchymal markers, which suggested that miR-149 regulated migration and invasion by repressing EMT. The present results suggested that miR-149 attenuates the aggressiveness of C4-2 cells and acts as a tumor suppressor gene in CRPC cells.

The PI3K/Akt signaling pathway is one of the most commonly dysregulated pathways in malignant cells.
Aberrant activity of the PI3K/Akt signaling pathway has been found at early and advanced stages of PCa (25). Akt1, a serine/threonine-protein kinase, phosphorylates the key molecules, leading to increased cellular growth and survival (26). Over previous years, several studies have indicated that the PI3K/Akt signaling pathway is regulated by miRNAs in various types of cancer (27-29). It has been reported that miR-26a can activate the PI3K/Akt signaling pathway by inhibiting the expression of PTEN, thus suggesting that miR-26a may be a potential therapeutic target for lung cancer (30). Furthermore, a number of previous 
A

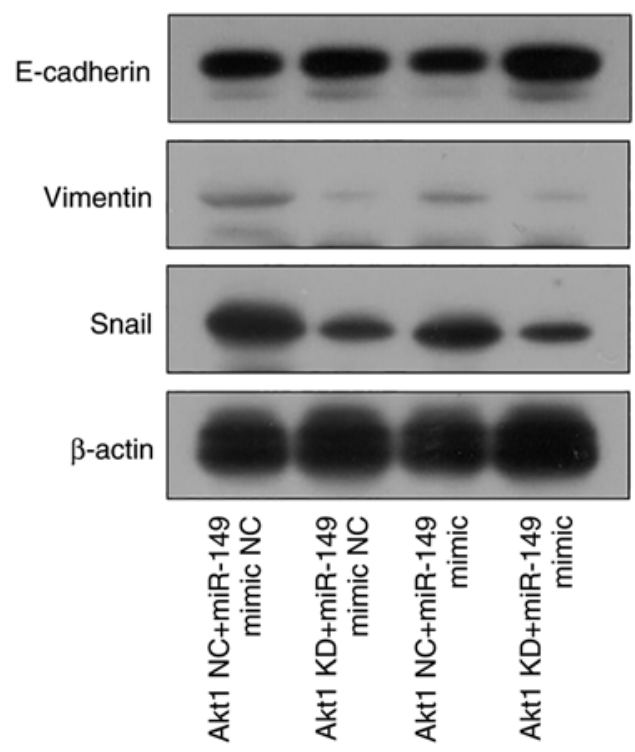

C

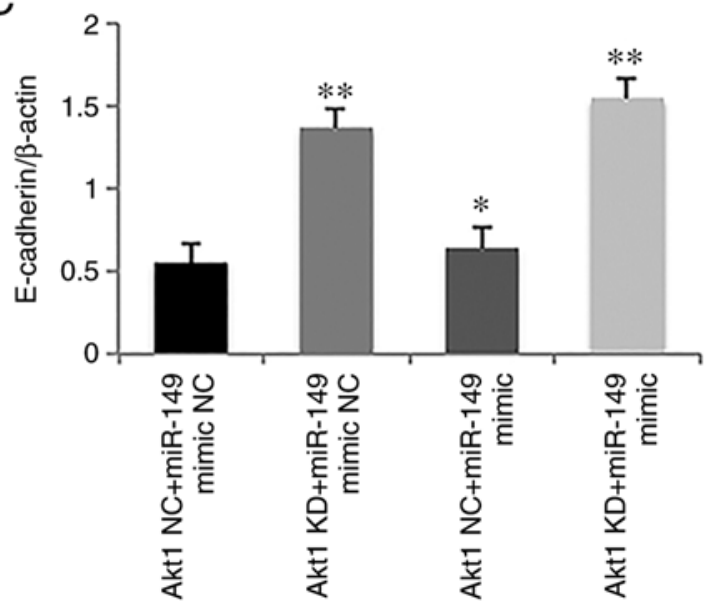

B

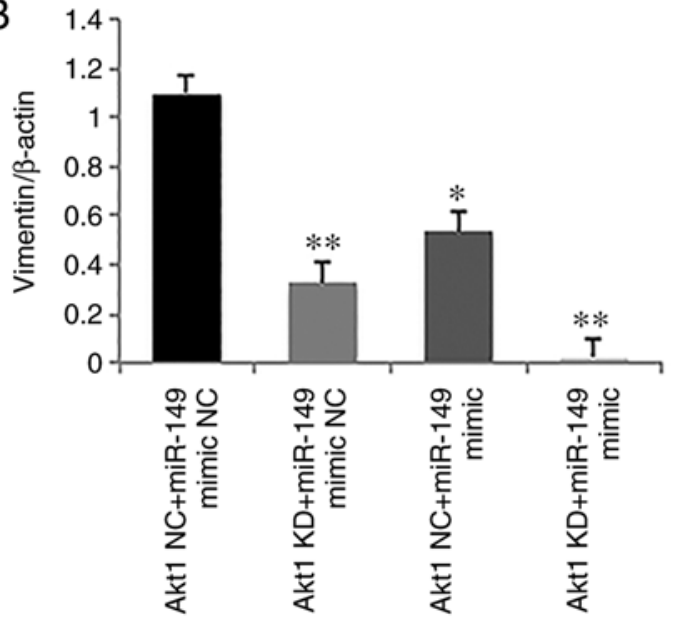

D

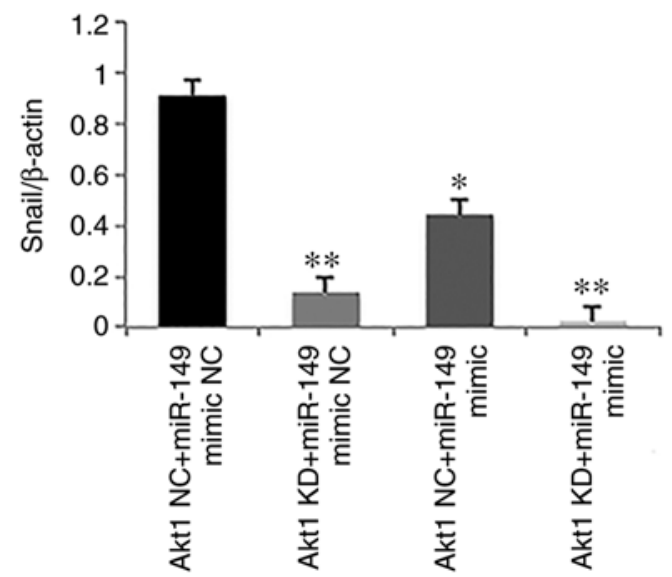

Figure 6. Effects of miR-149 on the expression of EMT markers in castration-resistant prostate cancer cell line. (A) Western blotting as performed to analyze the effect of transfection with Akt1 NC + miR-149 mimic NC, Akt1 KD + miR-149 mimic NC, Akt1 NC + miR-149 mimic or Akt1 KD + miR-149 mimic on the expression of EMT markers in C4-2 cells. (B-D) Semi-quantification of western blot analysis revealed that miR-149 mimics and Akt1-shRNA could increase the expression of epithelial marker E-cadherin and decrease the expression of mesenchymal markers Vimentin and Snail in C4-2 cells. Data are expressed as the mean \pm standard deviation $(n=3) .{ }^{*} \mathrm{P}<0.05,{ }^{* *} \mathrm{P}<0.01$ vs. Akt1 $\mathrm{NC}+$ miR-149 mimic NC group. miR, microRNA; EMT, epithelial-mesenchymal transition; NC, negative control; KD, knockdown; shRNA, short hairpin RNA.

studies have reported that miR-149 can suppress cancer cell malignant phenotypes by regulation of Akt1 in a number of different types of human cancers $(22,31,32)$. Zhang et al (22) also reported that miR-149 plays a tumor-suppressive role by targeting Akt1 expression in human HCC. This study also identified that the increased expression of miR-149 significantly inhibited HCC cell proliferation and invasion by regulating the PI3K/Akt signaling pathway (22).

Consistent with our previous study, the current study found that the PI3K/Akt signaling pathway is regulated by miR-149 in CRPC cells. Mechanistically, miR-149 could inhibit the expression of Aktl at the mRNA level, reducing the expression of total Akt1 and p-Akt1 protein, thus inhibiting the expression of mTOR, the target gene of the PI3K/Akt signaling pathway. PTEN is a critical regulator of PI3K/Akt signaling, which can inhibit the phosphorylation of Akt1 protein, thus inhibiting the functional activity of the PI3K/Akt signal pathway (29). These results indicated that miR-149 regulated Akt1 expression via targeting Akt1 mRNA rather than regulating $\mathrm{PI} 3 \mathrm{~K}, \mathrm{p}-\mathrm{PI} 3 \mathrm{~K}$ and PTEN expression.

In addition, Akt1-shRNA was also used to investigate the effect of the PI3K/Akt signaling pathway on the aggressiveness of CRPC cells. As a result, it was found that knockdown of Akt1 had a similar tumor suppressive effect as miR-149 mimics, which could inhibit cell invasion and proliferation, and induce cell cycle arrest and apoptosis of CRPC cells.

AR belongs to the steroid hormone subfamily of nuclear hormone receptors and mediates the signaling of androgens (3). Despite failures in treating recurrent CRPC, it is widely accepted that AR signaling is a driving force in CRPC progression; thus, drugs reducing AR levels and AR activity are likely to be effective in CRPC treatment $(33,34)$. Unfortunately, acquired drug resistance is an increasing clinical problem, so novel biomarkers and treatments for PCa and CRPC are urgently needed (35). The PI3K/Akt and AR signaling pathways have been shown to cross-regulate 
through reciprocal inhibitory activity (8). Consequently, the PI3K/Akt signaling pathway can be activated in response to androgen or AR blockade therapy in human $\mathrm{PCa}$, facilitating CRPC growth; vice versa, inhibition of the PI3K/Akt signaling pathway can augment AR signaling, thus leading to therapeutic resistance $(6,8)$. In addition, it has also been reported that $\mathrm{AR}$ is an additional substrate for Akt, which can phosphorylate AR and inhibit AR target genes from inducing CRPC apoptosis (36).

The present study demonstrated that AR expression was regulated by miR-149 and the PI3K/Akt signaling pathway. Silencing of Akt1 by Akt1-shRNA inhibited the expression of AR, attenuated the proliferation and invasion, and induced apoptosis of CRPC cells. These results furthered the understanding of the roles of the PI3K/Akt1 signaling pathway involved in AR-regulated PCa progression and the classic roles of AR in PI3K/Akt-mediated cancer cell apoptosis. The association between the PI3K/Akt and AR signaling pathways could provide another perspective for investigating cancer cell growth and apoptosis.

The present study has several limitations. First, only one type of CRPC cell was used for the in vitro cell assay. In addition, the effect of miR-149 on the malignant phenotypes in CRPC was not investigated in vivo in this study. Further experiments are still required to explore the role of the miR-149/Akt1 signaling pathway in the progression of CRPC.

In conclusion, it was demonstrated that ectopic miR-149 could inhibit the expression levels of AR, PSA and AR-driven genes in C4-2 cells in association with a blockade of Akt1 inactivation, thus leading to alterations of gene expression involved in cell cycle progression, migration, invasion and apoptosis. These findings uncovered the potential role of the miR-149/Akt1 signaling pathway in the progression of CRPC, which indicated that inhibition of Akt1 expression via miR-149 overexpression could be a novel therapeutic target for the treatment of CRPC. Inhibition of oncogenic miRNAs or delivery of tumor-suppressive miRNAs could become a novel treatment strategy for $\mathrm{PCa}$.

\section{Acknowledgements}

Not applicable.

\section{Funding}

The present study was supported by the National Natural Science Foundation of Beijing (grant no. 7192053).

\section{Availability of data and materials}

The datasets used and/or analyzed during the current study are available from the corresponding author on reasonable request.

\section{Authors' contributions}

YJ and YL made substantial contributions to the conception and design of the present study. QL, JZ, BF, DW, YH, YW and ML conducted data acquisition, analysis and interpretation. JZ and QL drafted the article and critically revised it for important intellectual content. All authors have read and approved the final manuscript. YL, JZ and QL agreed to be accountable for all aspects of the work in ensuring that questions related to the accuracy or integrity of the work are appropriately investigated and resolved. All authors provided critical feedback and helped shape the research, analysis, and manuscript. JZ, QL, YJ and YL confirm the authenticity of all the raw data.

\section{Ethics approval and consent to participate}

Not applicable.

\section{Patient consent for publication}

Not applicable.

\section{Competing interests}

The authors declare that they have no competing interests.

\section{References}

1. Torre LA, Siegel RL, Ward EM and Jemal A: Global cancer incidence and mortality rates and trends-an update. Cancer Epidemiol Biomarkers Prev 25: 16-27, 2016.

2. Ritch $C$ and Cookson M: Recent trends in the management of advanced prostate cancer. F1000Res 7: 1513, 2018.

3. Dai C, Heemers H and Sharifi N: Androgen signaling in prostate cancer. Cold Spring Harb Perspect Med 7: a030452, 2017.

4. Teo MY, Rathkopf DE and Kantoff P: Treatment of advanced prostate cancer. Annu Rev Med 70: 479-499, 2019.

5. Bastos D and Antonarakis E: CTC-derived AR-V7 detection as a prognostic and predictive biomarker in advanced prostate cancer. Expert Rev Mol Diagn 18: 155-163, 2018.

6. Shorning BY, Dass MS, Smalley MJ and Pearson HB: The PI3K-AKT-mTOR pathway and prostate cancer: At the crossroads of AR, MAPK, and WNT signaling. Int J Mol Sci 21: 4507, 2020.

7. Edlind MP and Hsieh AC: PI3K-AKT-mTOR signaling in prostate cancer progression and androgen deprivation therapy resistance. Asian J Androl 16: 378-386, 2014.

8. Lee SH, Johnson D, Luong R and Sun Z: Crosstalking between androgen and PI3K/AKT signaling pathways in prostate cancer cells. J Biol Chem 290: 2759-2768, 2015.

9. Wang K, Ruan H, Xu T, Liu L, Liu D, Yang H, Zhang X and Chen K: Recent advances on the progressive mechanism and therapy in castration-resistant prostate cancer. Onco Targets Ther 11: 3167-3178, 2018.

10. Rafiei S, Gui B, Wu J, Liu XS, Kibel AS and Jia L: Targeting the MIF/CXCR7/AKT signaling pathway in castration-resistant prostate cancer. Mol Cancer Res 17: 263-276, 2019.

11. He Y, Yu D, Zhu L, Zhong S, Zhao J and Tang J: miR-149 in human cancer: A systemic review. J Cancer 9: 375-388, 2018.

12. Xie Z, Xu J, Peng L, Gao Y, Zhao H and Qu Y: miR-149 promotes human osteocarcinoma progression via targeting bone morphogenetic protein 9 (BMP9). Biotechnol Lett 40: 47-55, 2018.

13. Li Y, Ju K, Wang W, Liu Z, Xie H, Jiang Y, Jiang G, Lu J, Dong Z and Tang F: Dinitrosopiperazine-decreased PKP3 through upregulating miR-149 participates in nasopharyngeal carcinoma metastasis. Mol Carcinog 57: 1763-1779, 2018.

14. Ma J, Wei H, Li X and Qu X: hsa-miR-149-5p suppresses prostate carcinoma malignancy by suppressing RGS17. Cancer Manag Res 13: 2773-2783, 2021.

15. Wang C, Ding T, Yang D, Zhang P, Hu X, Qin W and Zheng J: The IncRNA OGFRP1/miR-149-5p/IL-6 axis regulates prostate cancer chemoresistance. Pathol Res Pract 224: 153535, 2021.

16. Fujii T, Shimada K, Tatsumi Y, Fujimoto K and Konishi N: Syndecan-1 responsive microRNA-126 and 149 regulate cell proliferation in prostate cancer. Biochem Biophys Res Commun 456: 183-189, 2015.

17. Chen Y, Zhao J, Luo Y, Wang Y and Jiang Y: Downregulated expression of miRNA-149 promotes apoptosis in side population cells sorted from the TSU prostate cancer cell line. Oncol Rep 36: 2587-2600, 2016 
18. Wu HC, Hsieh JT, Gleave ME, Brown NM, Pathak S and Chung LW: Derivation of androgen-independent human LNCaP prostatic cancer cell sublines: Role of bone stromal cells. Int J Cancer 57: 406-412, 1994.

19. Livak KJ and Schmittgen TD: Analysis of relative gene expression data using real-time quantitative PCR and the 2(-Delta Delta C(T)) method. Methods 25: 402-408, 2001.

20. Odero-Marah V, Hawsawi O, Henderson V and Sweeney J: Epithelial-mesenchymal transition (EMT) and prostate cancer. Adv Exp Med Biol 1095: 101-110, 2018.

21. Zhi Y, Zhou H, Mubalake A, Chen Y, Zhang B, Zhang K, Chu X and Wang R: Regulation and functions of MicroRNA-149 in human cancers. Cell Prolif 51: e12465, 2018.

22. Zhang Y, Guo X, Xiong L, Yu L, Li Z, Guo Q, Li Z, Li B and Lin N: Comprehensive analysis of microRNA-regulated protein interaction network reveals the tumor suppressive role of microRNA-149 in human hepatocellular carcinoma via targeting AKT-mTOR pathway. Mol Cancer 13: 253, 2014.

23. Fogli S, Polini B, Carpi S, Pardini B, Naccarati A, Dubbini N, Lanza M, Breschi MC, Romanini A and Nieri P: Identification of plasma microRNAs as new potential biomarkers with high diagnostic power in human cutaneous melanoma. Tumour Biol 39: 1010428317701646, 2017

24. Montanari M, Rossetti S, Cavaliere C, D'Aniello C, Malzone MG, Vanacore D, Di Franco R, La Mantia E, Iovane G, Piscitelli R, et al: Epithelial-mesenchymal transition in prostate cancer: An overview. Oncotarget 8: 35376-35389, 2017.

25. Chen H, Zhou L, Wu X, Li R, Wen J, Sha J and Wen X: The $\mathrm{PI} 3 \mathrm{~K} / \mathrm{AKT}$ pathway in the pathogenesis of prostate cancer. Front Biosci (Landmark Ed) 21: 1084-1091, 2016.

26. Nóbrega M, Cilião HL, Souza MF, Souza MR, Serpeloni JM, Fuganti PE and Cólus IMS: Association of polymorphisms of PTEN, AKT1, PI3K, AR, and AMACR genes in patients with prostate cancer. Genet Mol Biol 43: e20180329, 2020.

27. Hu M, Zhu S, Xiong S, Xue X and Zhou X: MicroRNAs and the PTEN/PI3K/Akt pathway in gastric cancer (Review). Oncol Rep 41: 1439-1454, 2019.
28. Ghafouri-Fard S, Shoorei H and Taheri M: miRNA profile in ovarian cancer. Exp Mol Pathol 113: 104381, 2020.

29. Wise HM, Hermida MA and Leslie NR: Prostate cancer, PI3K, PTEN and prognosis. Clin Sci (Lond) 131: 197-210, 2017.

30. Chen J, Xu Y, Tao L, Pan Y, Zhang K, Wang R, Chen LB and Chu X: miRNA-26a contributes to the acquisition of malignant behaviors of doctaxel-resistant lung adenocarcinoma cells through targeting EZH2. Cell Physiol Biochem 41: 583-597, 2017.

31. Niu Y, Tang G, Wu X and Wu C: LncRNA NEAT1 modulates sorafenib resistance in hepatocellular carcinoma through regulating the miR-149-5p/AKT1 axis. Saudi J Gastroenterol 26: 194-203, 2020.

32. Pan SJ, Zhan SK, Pei BG, Sun QF, Bian LG and Sun BM: MicroRNA-149 inhibits proliferation and invasion of glioma cells via blockade of AKT1 signaling. Int J Immunopathol Pharmacol 25: 871-881, 2012.

33. De Nunzio C, Presicce F, Giacinti S, Bassanelli M and Tubaro A: Castration-resistance prostate cancer: What is in the pipeline? Minerva Urol Nefrol 70: 22-41, 2018.

34. Galletti G, Leach BI, Lam L and Tagawa ST: Mechanisms of resistance to systemic therapy in metastatic castration-resistant prostate cancer. Cancer Treat Rev 57: 16-27, 2017.

35. James ND, de Bono JS, Spears MR, Clarke NW, Mason MD, Dearnaley DP, Ritchie AWS, Amos CL, Gilson C, Jones RJ, et al: Abiraterone for prostate cancer not previously treated with hormone therapy. N Engl J Med 377: 338-351, 2017.

36. Yan $\mathrm{Y}$ and Huang H: Interplay among PI3K/AKT, PTEN/FOXO and AR signaling in prostate cancer. Adv Exp Med Biol 1210: 319-331, 2019.

This work is licensed under a Creative Commons Attribution-NonCommercial-NoDerivatives 4.0 International (CC BY-NC-ND 4.0) License. 